\title{
Neurofascin antibodies in autoimmune, genetic, and idiopathic neuropathies
}

Elisabeth Burnor, BA, Li Yang, MD, Hao Zhou, MD, Kristina R. Patterson, MD, PhD, Colin Quinn, MD, MS, Mary M. Reilly, FRCP, FRCPI, MD, Alexander M. Rossor, MRCP, PhD, Steven S. Scherer, MD, PhD, and Eric Lancaster, MD, PhD

Neurology 2018;90:e31-38. doi:10.1212/WNL.0000000000004773

\section{Abstract}

\section{Objective}

To measure the frequency, persistence, isoform specificity, and clinical correlates of neurofascin antibodies in patients with peripheral neuropathies.

\section{Methods}

We studied cohorts of patients with Guillain-Barre syndrome (GBS) or chronic inflammatory demyelinating polyneuropathy (CIDP) $(n=59)$, genetic neuropathy $(n=111)$, and idiopathic neuropathy $(n=43)$ for immunoglobulin $(\mathrm{Ig}) \mathrm{G}$ and $\operatorname{IgM}$ responses to 3 neurofascin (NF) isoforms (NF140, NF155, and NF186) using cell-based assays.

\section{Results}

Neurofascin antibodies were more common in patients with GBS/CIDP (14\%, 8 of 59) compared to genetic neuropathy controls ( $3 \%, 3$ of $111, p=0.01)$. Seven percent ( 3 of 43 ) of patients with idiopathic neuropathy also had neurofascin antibodies. NF155 IgG4 antibodies were associated with CIDP refractory to IV immunoglobulin but responsive to rituximab, and some of these patients had an acute onset resembling GBS. NF186 IgG and IgM to either isoform were less specific. A severe form of CIDP, approaching a locked-in state, was seen in a patient with antibodies recognizing all 3 neurofascin isoforms.

\section{Conclusions}

Neurofascin antibodies were 4 times more frequent in autoimmune neuropathy samples compared to genetic neuropathy controls. Persistent IgG4 responses to NF155 correlated with severe CIDP resistant to usual treatments but responsive to rituximab. IgG4 antibodies against the common domains shared by glial and axonal isoforms may portend a particularly severe but treatable neuropathy. The prognostic implications of neurofascin antibodies in a subset of idiopathic neuropathy patients and transient IgM responses in GBS require further investigation.

\author{
Correspondence \\ Dr. Lancaster \\ Eric.lancaster@uphs. \\ upenn.edu
}

From the Department of Neurology (E.B., K.R.P., C.Q., S.S.S., E.L.), University of Pennsylvania, Philadelphia; Department of Neurology (L.Y., H.Z.), Second Xiangya Hospital of Central South University, Changsha, China; and MRC Centre for Neuromuscular Diseases (M.M.R., A.M.R.), UCL Institute of Neurology and National Hospital for Neurology and Neurosurgery, London, UK.

The Article Processing Charge was funded by University College London and the Wellcome Trust.

Go to Neurology.org/N for full disclosures. Funding information and disclosures deemed relevant by the authors, if any, are provided at the end of the article.

This is an open access article distributed under the terms of the Creative Commons Attribution License 4.0 (CC BY), which permits unrestricted use, distribution, and reproduction in any medium, provided the original work is properly cited. 


\section{Glossary}

CAM = cell adhesion molecule; CIDP = chronic inflammatory demyelinating polyneuropathy; $\mathbf{C M T}=$ Charcot-Marie-Tooth; DMEM = Dulbecco modified Eagle culture media; GBS = Guillain-Barre syndrome; IG = immunoglobulin; IVIG = IV immunoglobulin; NF = neurofascin.

Guillain-Barre syndrome (GBS) and chronic inflammatory demyelinating polyneuropathy (CIDP) are the 2 most common forms of autoimmune neuropathy. Both diseases are highly variable in the degree that sensory and motor axons are affected, the degree of demyelination and axonal injury, and the response to treatments. The immunologic basis of this variability is poorly understood.

Autoantibodies against membrane proteins expressed on axons or myelinating Schwann cells have recently been reported in some patients with CIDP or GBS. The target antigens are concentrated at nodes of Ranvier or at paranodes and are often cell adhesion molecules (CAMs) such as NrCAM, gliomedin, contactin-1, neurofascin (NF) 186, and NF155. ${ }^{1-7}$ Immunoglobulin (Ig) G4 antibodies to NF155 or its binding partner, contactin, have been associated with severe CIDP resistant to IV immunoglobulin (IVIG) treatment but potentially responsive to rituximab. ${ }^{2,7,8}$

We do not yet know the full utility of neurofascin antibodies in diagnosing autoimmune neuropathy or in guiding treatment. NF155 is localized to paranodes ${ }^{9}$ and microvilli of myelinating Schwann cells. ${ }^{10}$ NF186 and NF140 are localized to the axolemma mature and immature nodes, respectively. All are produced from the same neurofascin gene and share some subunits (figure 1A).,11 We have therefore tested the frequency, isoform specificity, and clinical correlates of neurofascin antibodies in autoimmune, genetic, and idiopathic neuropathy cohorts.

\section{Methods}

\section{Standard protocol approvals, registrations, and patient consents}

Cases with GBS, CIDP, idiopathic neuropathy, and CharcotMarie-Tooth (CMT) neuropathy were identified from our tissue bank at the University of Pennsylvania (Institutional Review Board protocol 816805). An additional 76 cases with a genetically confirmed diagnosis of CMT were identified at the National Hospital for Neurology and Neurosurgery, Queen Square Hospital, London, as approved by the National Hospital for Neurology and Neurosurgery Research Ethics Committee/Central London (REC 3 09/H0716/61). Of the 76 patients (39 male and 37 female patients, mean age 46 years), 49 had demyelinating CMT and $27 \mathrm{had}$ axonal CMT of the following subtypes: CMT1A $(\mathrm{n}=37)$, CMT1B $(\mathrm{n}=1)$, CMT1C $(n=1)$, CMT2A $(n=1)$, CMT2F $(n=5)$, CMT4B $(\mathrm{n}=1)$, CMTX1 $(\mathrm{n}=12)$, and hereditary sensory neuropathy due to SPTLC1 $(\mathrm{n}=20)$ and SPTLC2 $(\mathrm{n}=1)$ mutations.
Data analysis was conducted under Institutional Review Board protocol 820981 at the University of Pennsylvania.

\section{Neurofascin antibody detection and characterization}

Ad293 cells (Agilent Technologies, Santa Clara, CA) were plated on poly-D-lysine-coated coverslips (Neuvitro, Vancouver, WA) in fetal bovine serum-supplemented Dulbecco modified Eagle culture media (DMEM) and allowed to incubate for 24 hours. Cells were transfected with the pFLAG-CMV-5a,b,c expression vector containing mouse NF186 or the pcDNA3 expression vector containing rat NF155 (both courtesy of Dr. Peter Brophy, University of Edinburgh). Samples reactive against NF155 or NF186 were also tested against mouse NF140 with a plasmid also generated by Dr. Brophy. ${ }^{11}$ Cells were transiently transfected with the Jetprime Polyplus Transfection Reagent (Polyplus-transfection SA, IllkirchGraffenstaden, France). Four hours after transfection, the culture media was replaced with fresh DMEM, and cells were then allowed to incubate for another 16 to 20 hours.

Cells were live-stained with patient sera diluted (1:100) in DMEM for 30 minutes at $37^{\circ} \mathrm{C}$, fixed with $4 \%$ paraformaldehyde, permeabilized with $0.3 \%$ Triton X-100 (Sigma Aldrich, St. Louis, MO), and blocked with 5\% normal goat serum in PBS for 1 hour at room temperature before incubation with Alexa Fluor 488-conjugated goat anti-human $\operatorname{IgG}(\mathrm{H}+\mathrm{L})(1: 2,000)$ or $\operatorname{IgG} \mathrm{Fc}_{\gamma}(1: 2,000)$ antibodies (Jackson ImmunoResearch, West Grove, PA) or with Alexa Fluor 488-conjugated goat anti-human IgM antibodies $(1: 4,000)$ (Life Technologies, Carlsbad, CA) for 40 minutes at room temperature. Cells were then treated for 1 hour with polyclonal chicken anti-neurofascin primary antibodies (R\&D Systems, Minneapolis, MN), followed by Alexa Fluor 594conjugated goat anti-chicken $\operatorname{IgY}(\mathrm{H}+\mathrm{L})$ antibodies for 40 minutes $(1: 2,000)$. Cells were washed with PBS between incubations. Cells were mounted with DAPI Fluromount-G (Southern Biotech, Birmingham, AL). Staining results were visualized with a Leica fluorescent microscope.

\section{IgG subclasses}

IgG subtypes were determined by a live staining protocol. After blocking in 5\% normal goat serum in PBS, cells were labeled with ThermoFisher unconjugated mouse antibodies against IgG1 (1:200), IgG2 (1:1,000), IgG3 (1:500), or IgG4 (1:75) for 1 hour at room temperature, followed by Alexa Fluor 488-conjugated goat anti-mouse $\operatorname{IgG}(\mathrm{H}+\mathrm{L})$ antibodies $(1: 2,000)$ (Jackson ImmunoResearch) for 40 minutes. Cells were then washed and stained with anti-neurofascin antibodies as described above. 


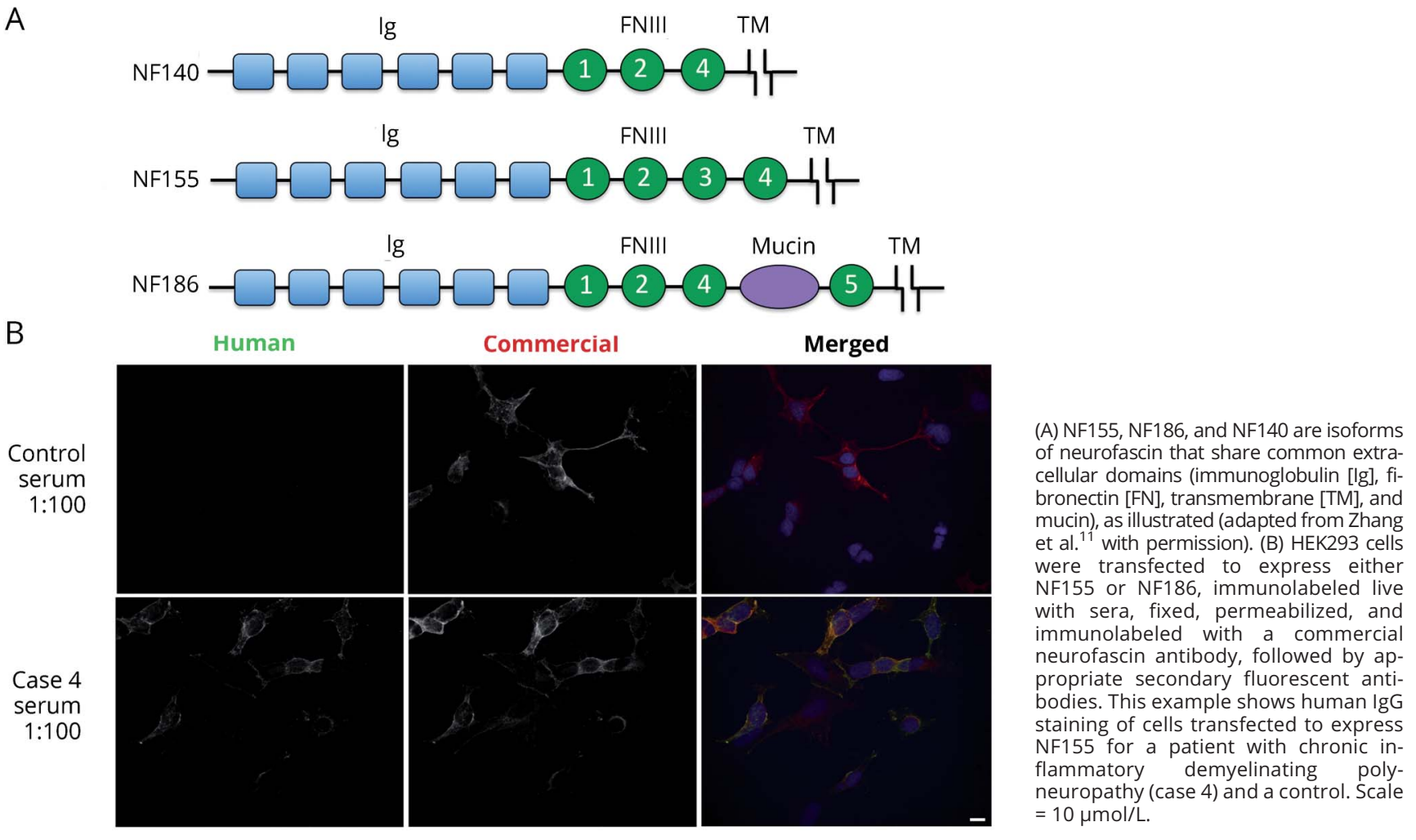

\section{Statistics}

Frequencies of the antibodies in the different groups were compared with the Fisher exact test.

\section{Results}

\section{Neurofascin antibody frequency}

We screened sera from our cohorts of patients for IgG and IgM autoantibodies to NF155 and NF186 using cell-based assays (examples shown in figure 1B). Neurofascin antibodies were more common in patients with GBS/CIDP (14\%, 8 of 59) compared to controls with genetic neuropathy ( $3 \%, 3$ of 111 , $p=0.01)$. Patients with idiopathic neuropathy had intermediate frequency of the antibodies (7\%, 3 of 43 , not significantly different from other groups). The characteristics of antibody-positive patients with GBS and CIDP are presented in table 1 .

\section{IgG responses to NF155}

We detected NF155 IgG binding in 4 of $40(10 \%)$ patients with CIDP, 0 of $14(0 \%)$ patients with GBS, and 1 of 111 (1\%) patients with CMT, indicating a low false-positive rate. None $(0$ of 43) of our idiopathic neuropathy patients had NF155 IgG.

The case with CMT was a 34-year-old man with a c.374T $>\mathrm{C}$ (p.Leu125Pro) mutation in LITAF that was deemed to be pathogenic because of its absence in control databases, segregation with the disease in other affected family members, and the large physicochemical difference between leucine and proline.

The sera with NF155 IgG were studied with subtype-specific secondary antibodies for IgG1, IgG2, IgG3, and/or IgG4 (table 2). Our patients with CIDP with IgG to N155 all had IgG4-predominant responses, consistent with prior reports. ${ }^{2,8}$ The single patient with CMT1 and NF155 IgG had a high titer $(1: 3,200)$ that was predominantly $\operatorname{IgG} 1$; no $\operatorname{IgG} 2$ through IgG4 antibodies were detected.

Our patients with CIDP with NF155 IgG antibodies share important features with previously reported patients. ${ }^{2}$ Specifically, 3 patients had high CSF protein; severe, progressive CIDP; and poor response to IVIG treatment. After rituximab, 2 of the 3 patients showed marked improvement, and the third patient appears to be responding 3 months after treatment. None of them showed disabling tremor, in contrast to prior reports. Case 3 (table 1) had coexisting NF155 IgG and anti-myelinassociated glycoprotein antibodies (with IgMк paraprotein), although her clinical course was similar to that of the other patients with NF155 IgG. Specifically, she had progressive distal and proximal weakness with loss of ability to ambulate over several months and then rapidly improved after rituximab, a pattern more typical of NF155-positive patients than patients with distal acquired demyelinating symmetric neuropathy. ${ }^{12}$ 
Table 1 Characteristics of autoimmune neuropathy patients with neurofascin antibodies

\begin{tabular}{|c|c|c|c|c|}
\hline $\begin{array}{l}\text { Case/ } \\
\text { diagnosis/ } \\
\text { sex }\end{array}$ & $\begin{array}{l}\text { Antibody } \\
\text { and titer }\end{array}$ & Symptoms & Treatments (responses) & EMG and CSF protein \\
\hline $1 / \mathrm{CIDP} / \mathrm{F}$ & $\begin{array}{l}\text { NF155/IgG } \\
\text { and IgM/1: } \\
200\end{array}$ & $\begin{array}{l}\text { Chronic relapsing CIDP starting at age } 13 \text {. } \\
\text { Events progress over } 4-6 \text { wk, causing inability } \\
\text { to walk, multifocal numbness, and areflexia. } \\
\text { Good recovery between events. }\end{array}$ & $\begin{array}{l}\text { Prednisone (yes); IVIG and } \\
\text { apheresis (not clear if effective) }\end{array}$ & $\begin{array}{l}\text { Mild distal symmetric polyneuropathy } \\
\text { (between attacks); CSF protein NA }\end{array}$ \\
\hline 2/CIDP/M & $\begin{array}{l}\text { NF155 lgG/ } \\
1: 800 / \\
\text { NF186 lgG/ } \\
1: 1,600\end{array}$ & $\begin{array}{l}\text { At age } 50, \text { rapidly progressive weakness and } \\
\text { paresthesias, evolved into extraocular } \\
\text { weakness, ptosis, facial diplegia, dysarthria, } \\
\text { nearly complete ophthalmoplegia, } \\
\text { quadriplegia, and oscillating sympathetic } \\
\text { hypersensitivity with labile blood pressure. } \\
\text { See case report in text. }\end{array}$ & $\begin{array}{l}\text { IVIG (initially yes, later no); } \\
\text { plasmapheresis (initially yes, } \\
\text { before worsening again); } \\
\text { rituximab and } \\
\text { cyclophosphamide (yes) }\end{array}$ & $\begin{array}{l}\text { Diagnostic features of acquired, } \\
\text { demyelinating polyneuropathy with } \\
\text { evidence of severe axonal loss; CSF protein } \\
106.1 \mathrm{mg} / \mathrm{dL}\end{array}$ \\
\hline 3/CIDP/F & $\begin{array}{l}\text { NF155 lgG/ } \\
1: 1,600\end{array}$ & $\begin{array}{l}\text { At age 54, presented with 6-8 wk of progressive } \\
\text { numbness of all extremities, sensory ataxia, and } \\
\text { weakness. Became bedbound with impaired use } \\
\text { of the hands. Positive for anti-MAG antibodies, } \\
\text { initially diagnosed with DADS neuropathy before } \\
\text { severe progressive disability. }\end{array}$ & $\begin{array}{l}\text { Prednisone (no); IVIG (no); } \\
\text { Rituximab and PLEX (yes) }\end{array}$ & $\begin{array}{l}\text { Demyelinating neuropathy with } \\
\text { prolongation of all distal latencies (most } \\
>130 \% \text { normal) and diffuse slowing; CSF } \\
\text { protein } 180 \mathrm{mg} / \mathrm{dL}\end{array}$ \\
\hline 4/CIDP/M & $\begin{array}{l}\text { NF155 lgG/ } \\
1: 3,200\end{array}$ & $\begin{array}{l}\text { At age 39, subacute-onset progressive } \\
\text { numbness of the feet and then hands, then } \\
\text { progressive weakness. Diagnosed with optic } \\
\text { neuritis/papilledema, which improved with } \\
\text { prednisone treatment. Refractory to steroids, } \\
\text { IVIG, Cytoxan. Stabilized and slight } \\
\text { improvement after rituximab. }\end{array}$ & $\begin{array}{l}\text { IVIG (no); plasmapheresis } \\
\text { (partial response); steroids (no); } \\
\text { cyclophosphamide (no); } \\
\text { rituximab (yes, stabilized) }\end{array}$ & $\begin{array}{l}\text { Severe, demyelinating sensory-motor } \\
\text { polyneuropathy. Motor conduction } \\
\text { velocities } 15-29 \mathrm{~m} / \mathrm{s} \text {; CSF protein } 550 \mathrm{mg} / \mathrm{dL}\end{array}$ \\
\hline 5/CIDP/M & $\begin{array}{l}\text { NF186/ } \\
\text { IgM/1: } \\
1,600\end{array}$ & $\begin{array}{l}\text { At age } 80,6 \text { wk of progressive numbness of } \\
\text { the limbs and then face, with weakness of all } \\
\text { extremities and face. Mild proximal and } \\
\text { moderate distal weakness, distal sensory loss, } \\
\text { and areflexia. Needed cane. Prior non-Hodgkin } \\
\text { lymphoma. }\end{array}$ & IVIG (yes) & $\begin{array}{l}\text { Severe sensory-motor neuropathy with } \\
\text { multifocal demyelinating features; CSF } \\
\text { protein } 82 \mathrm{mg} / \mathrm{dL}\end{array}$ \\
\hline 6/GBS/M & $\begin{array}{l}\text { NF155 } \\
\text { IgM/1: } \\
3,200\end{array}$ & $\begin{array}{l}\text { History of Henoch-Schonlein purpura. At age } \\
48, \text { had acute progressive areflexic weakness } \\
\text { after a cold. Sensory loss in extremities, } \\
\text { areflexia, and severe shoulder/back pain in } \\
\text { the acute phase. Became bedbound, unable to } \\
\text { use hands. He began improving during PLEX, } \\
\text { walked with a walker at } 2 \text { wk. At } 11 \text { mo, he had } \\
\text { normal strength and minimal sensory deficits. } \\
\text { A subsequent second attack occurred, but he } \\
\text { was lost to follow-up. }\end{array}$ & Plasmapheresis (yes) & $\begin{array}{l}\text { Acute neuropathy with multifocal } \\
\text { demyelinating features that improved } \\
\text { rapidly between } 2 \text { studies performed } 2 \\
\text { weeks apart, consistent with rapidly } \\
\text { resolving conduction blocks; CSF protein } 313 \\
\text { mg/dL }\end{array}$ \\
\hline $\begin{array}{l}\text { 7/AMAN/ } \\
\text { M }\end{array}$ & $\begin{array}{l}\text { NF186 } \\
\text { IgM/1: } \\
1,600\end{array}$ & $\begin{array}{l}\text { At age } 71 \text {, developed pain and weakness } \\
\text { starting } 5 \mathrm{~d} \text { after a diarrheal illness in Peru; } \\
\text { weakness of lower then upper extremities } \\
\text { with no significant sensory loss; areflexia. } \\
\text { Became bedbound and unable to use hands } \\
\text { within } 10 \mathrm{~d} \text {. Clinical diagnosis of AMAN. At } 14 \\
\text { mo, had residual moderate distal upper and } \\
\text { lower extremity weakness, walking with cane, } \\
\text { able to use buttons }\end{array}$ & $\begin{array}{l}\text { IVIG for } 5 \mathrm{~d} \text { (yes but slow recovery, } \\
\text { likely due to axonal damage) }\end{array}$ & $\begin{array}{l}\text { Severe acute motor-predominant axonal } \\
\text { neuropathy with marked reduction in motor } \\
\text { amplitudes; } 14 \text { mo of follow-up with interval } \\
\text { improvement in motor amplitudes; CSF } \\
\text { protein } 93 \mathrm{mg} / \mathrm{dL}\end{array}$ \\
\hline $8 / G B S / F$ & $\begin{array}{l}\text { NF186 } \\
\text { IgM/1: } \\
3,200\end{array}$ & $\begin{array}{l}\text { At age } 33 \text {, developed mild weakness and } \\
\text { tingling in toes, legs, and arms } 5 \mathrm{~d} \text { after } \\
\text { a Gl illness. Tingling and weakness } \\
\text { stabilized in a couple weeks, but severe } \\
\text { neuropathic pain persisted. High GQ1b } \\
\text { IgG/IgM-117 }\end{array}$ & NA & $\begin{array}{l}\text { Diffuse primarily demyelinating acquired } \\
\text { sensory-motor polyneuropathy; CSF protein } \\
\text { NA }\end{array}$ \\
\hline
\end{tabular}

Abbreviations: AMAN = acute motor axonal neuropathy; CIDP = chronic inflammatory demyelinating polyneuropathy; DADS = distal acquired demyelinating symmetric neuropathy; GBS = Guillain-Barre syndrome; GI = gastrointestinal; Ig = immunoglobulin; IVIG = IV immunoglobulin; MAG = myelin-associated glycoprotein; NA = not available; NF = neurofascin; PLEX = plasma exchange.

Case 2 had a more severe phenotype than previously reported and IgG4 recognizing NF140, NF155, and NF186. His clinical and immunologic characteristics are detailed below.

\section{Case report of a patient with IgG4 to all forms of neurofascin}

Starting 1 to 2 weeks after a diarrheal illness, a 50-year-old man developed 2 weeks of progressive ascending weakness and 
Table 2 IgG1 through IgG4 subclasses of IgG-positive patients

\begin{tabular}{|c|c|c|c|}
\hline Case & Diagnosis & Isoform reactivity and titer & IgG subtype (if IgG present and strong enough to subtype) \\
\hline 1 & CIDP & NF155 IgG and IgM 1:200 & Predominantly IgG4; also detected IgG1 and IgG2 \\
\hline 2 & CIDP & NF155 IgG 1:800; NF186 IgG 1:1,600 & Predominantly IgG4; also detected IgG1 and IgG2 \\
\hline 3 & CIDP & NF155 IgG 1:1,600 & Predominantly $\lg G 4$; also detected minimal $\lg G 1$ and $\lg G 2$ \\
\hline 4 & CIDP & NF155 IgG 1:3,200 & Detected IgG1, IgG2, and IgG4 \\
\hline 5 & CIDP & NF186 IgM 1:1,600 & - \\
\hline 6 & GBS & NF155 IgM 1:3,200 & - \\
\hline 7 & AMAN & NF186 IgM 1:1,600 & - \\
\hline 8 & GBS & NF186 IgM 1:3,200 & - \\
\hline 9 & Idiopathic neuropathy & NF155 IgM 1:400 & - \\
\hline 10 & Idiopathic Neuropathy & NF186 IgG 1:800 & Detected minimal IgG4 \\
\hline 11 & Idiopathic neuropathy & NF186 IgM 1:800 & - \\
\hline 12 & CMT & NF155 IgM 1:200 & - \\
\hline 13 & CMT & NF155 IgG 1:3,200 & Predominantly IgG1, No IgG2, IgG3, or IgG4 detected \\
\hline 14 & CMT & NF155 IgM 1:100 & - \\
\hline
\end{tabular}

Abbreviations: AMAN = acute motor axonal neuropathy; CIDP = chronic inflammatory demyelinating polyneuropathy; CMT = Charcot-Marie-Tooth; GBS = Guillain-Barre syndrome; $\mathrm{Ig}=$ immunoglobulin; $\mathrm{NF}=$ neurofascin.

paresthesias. On presentation, his examination was notable for proximal and distal weakness and areflexia. A lumbar puncture demonstrated mildly elevated protein $(60 \mathrm{mg} / \mathrm{dL})$ but was otherwise unremarkable. He received $2 \mathrm{~g} / \mathrm{kg}$ IVIG over 5 days with dramatic improvement and was discharged home 1 day after completing treatment.

Within 3 to 4 days of discharge, the ascending weakness and paresthesias returned. On examination, he was areflexic and had decreased sensation of cold, pinprick, and light touch distally in all extremities. His strength was $2 / 5$ to $4 / 5$ (Medical Research Council scale) in all upper extremity muscle groups bilaterally, weaker proximally. Repeat CSF protein was 106 $\mathrm{mg} / \mathrm{dL}$. EMG with nerve conduction studies showed prolonged tibial and peroneal $\mathrm{F}$ waves and preserved sensory responses with severely reduced recruitment in multiple proximal limb muscles. He did not meet electrodiagnostic criteria for CIDP..$^{13}$ His GQ1b, HIV, and Lyme antibodies, skeletal survey, and serum immunofixation were normal.

He was again treated with IVIG ( $2 \mathrm{~g} / \mathrm{kg}$ total) but continued to decline; he had limited extraocular muscle motility, ptosis, facial diplegia, dysarthria, and $0 / 5$ limb strength throughout with the exception of $2 / 5$ in finger movements and $3 / 5$ dorsiflexion. Repeat EMG with nerve conduction studies showed prolonged distal motor latencies and prolonged $\mathrm{F}$ waves diagnostic of CIDP and absent sensory responses. He was treated with a third course of IVIG. One week after transfer, he was intubated for increased secretions and worsening respiratory status. At that time, he had nearly complete ophthalmoplegia, weak cough and gag, $1 / 5$ neck flexion, and quadriplegia. He also had oscillating sympathetic hypersensitivity with labile blood pressure.

Plasmapheresis and IV solumedrol were initiated, with transient improvement. His facial strength improved to the point that lip reading was possible, and he recovered some eye movement. His ptosis improved, and he was able to lift his head off the bed. On day 36 , he recovered the ability to wiggle his fingers and toes, but he soon worsened. Cyclophosphamide $\left(750 \mathrm{mg} / \mathrm{m}^{2}\right)$ was initiated on day 52 for the first of 3 monthly doses. At this point, he was communicating by protruding his tongue for "yes." A second course of IV solumedrol and a second round of plasmapheresis were initiated, and his examination improved. He was able to open his eyes, to move his eyes in all directions, and to move his lips to mouth words. However, he developed aspiration pneumonia, and he again became essentially "locked in," unable to move. A third round of plasmapheresis was initiated, and he received his second dose of monthly cyclophosphamide. On day 86 , he received his first of 3 weekly doses of rituximab $\left(375 \mathrm{mg} / \mathrm{m}^{2}\right)$. On day 104 , his ophthalmoparesis began improving, and he was able to move his jaw. Over the course of the next 2 weeks, he was able to open his eyes, stick out his tongue, and nod his head. He was transferred to a long-term ventilator facility.

Ten months after his initial presentation, he was transferred to acute rehabilitation, decannulated, and gradually advanced to a normal diet. At the last follow-up 19 months after symptom onset, he was able to ambulate with bilateral ankle-foot 
orthotics, drive, and grip utensils. There was still severe weakness of all ankle and foot movements, as well as moderate weakness of intrinsic hand muscles.

\section{IgG responses to NF186}

In addition to case 2, a low-titer NF186 IgG response (without coexisting NF155 reactivity) was detected in 1 patient with idiopathic neuropathy. No other cases of CIDP, GBS (0 of 14), or CMT (0 of 111$)$ were associated with isolated reactivity to NF186.

\section{IgM responses to NF155 or NF186}

IgM responses to NF155 or NF186 were detected in 5 of 59 (8\%) patients with autoimmune neuropathy: 2 with CIDP (cases 1 and 5), 1 with acute inflammatory demyelinating polyneuropathy (case 6), 1 with acute motor axonal neuropathy (case 7), and 1 with features of CIDP and GBS (case 8). One patient with CIDP (case 1) had IgM against NF155 with a coexisting IgG4 response to NF155. IgM responses to NF186 or NF155 were also detected in 2 of 111 (2\%) patients with CMT and 2 of 43 (5\%) patients with idiopathic neuropathy. The 2 cases with CMT included a 78-year-old man with CMT1A and a relatively mild phenotype as defined by a CMT examination score of 7 and CMT neuropathy score of 12 and a patient with progressive neuropathy from age 3 without a definitely identified mutation.

\section{Epitope mapping of neurofascin IgG responses} NF155, NF186, and NF140 share some subunits in their extracellular domains (figure 1A). To determine the target epitopes of our NF155 or NF186 IgG-positive samples, we used cell-based assays for each of the 3 isoforms (figure 2). Isoform specificity and titers are summarized in table 2 . Three of 4 sera with NF155 IgG responses did not recognize NF186 or NF140. These patients most likely had antibodies against epitopes involving the third fibronectin-like domain, which is the only domain expressed in NF155 that is not present in both NF186 and NF140. Case 2, however, had strong IgG reactivity against all 3 neurofascin isoforms, indicating that at least 1 target epitope was in a domain that was shared by all 3 neurofascin isoforms. Because all of the domains of NF140 are also present in NF155 and NF186, a response to NF140 is sufficient to explain his response to NF155 and NF186, but this does not exclude the possibility that his antibodies also recognize domains specific to NF155 or NF186.

\section{Persistence of responses over time}

When possible, we analyzed follow-up samples from CIDP and neurofascin reactivity. Follow-up samples from 2 patients with NF155 IgG were studied. Case 2 provided samples during initial onset, 2 months later (during severe symptoms), and 19 months later, after the patient had significant recovery. The first 2 samples showed strong NF140, NF155, and NF186 IgG reactivity, whereas the final sample was negative for all neurofascin isoforms. In contrast, case 1, who had relapsing/ remitting CIDP, had 2 samples collected 2 years apart, both of which were positive (she had had no attacks in years).
Follow-up samples were also obtained for 3 patients with IgM responses but no IgG responses. Case 5, who had CIDP and responded to IVIG treatment, continued to have IgM antibodies against NF186 over the course of 8 months, during which time 4 samples were collected at 2- to 4-month intervals and the patient was still experiencing weakness but much improved symptoms as a result of regular IVIG infusions. Cases 6 and 7 had GBS and acute motor axonal neuropathy, respectively. Case 6 had IgM against NF155, and case 7 had IgM against NF186 during acute illness. Follow-up samples, after acute symptoms had subsided, were negative for IgM or IgG antibodies. Case 6 subsequently experienced a relapse of his neuropathy but was lost to follow-up.

\section{Discussion}

We comprehensively examined the frequency, clinical correlates, isoform specificity, and persistence of neurofascin antibodies in patients with diverse kinds of neuropathy. Our study supports the specific association of NF155 IgG4 with severe CIDP refractory to IVIG but often responsive to rituximab. These responses were specific to the NF155 isoform for most cases. Transient responses, often IgM, occurred in some patients with GBS. In addition, we found a higher frequency of neurofascin responses in idiopathic neuropathy compared to genetic neuropathy. Finally, we have reported a patient with incredibly severe but treatable neuropathy associated with autoimmunity to the common domains shared by all neurofascin isoforms.

Neurofascin antibodies were first reported in the context of multiple sclerosis ${ }^{14}$ and later in GBS. ${ }^{15}$ Subsequent reports have described NF155 and/or NF186 IgM or IgG responses in $1 \%$ to $18 \%$ of patients with GBS and CIDP, depending on the diagnosis and type of antibody. ${ }^{1}$ An association of NF155 IgG with CIDP particularly became clearer in subsequent reports, ${ }^{4}$ followed by the association of NF155 IgG4 with CIDP resistant to IVIG treatment and responsive to rituximab in small groups of patients. ${ }^{2,8,16}$ Most recently, a study of 246 patients with CIDP found 5 patients (2\%) with IgG4-predominant responses to the common epitopes of NF140, NF186, and NF155. ${ }^{17}$ These patients generally had subacute onset, prominent sensory ataxia, and sometimes cranial nerve involvement. While these patients had some similarities to case 2, none were as severely affected. As with our case, clinical remission correlated with resolution of the antibody response.

NF155 IgG4 was found in 10\% of our patients with CIDP, so screening appropriate patients may be clinically useful. One case had coexisting myelin-associated glycoprotein antibodies and met criteria for distal acquired demyelinating symmetric neuropathy but was otherwise similar to our other NF155 IgGpositive cases.

Transient IgM responses to neurofascin occurred in some of our patients with GBS, and some of our patients with NF155 IgG4 initially presented with an acute-onset neuropathy 
Figure 2 Isoform specificity of neurofascin (NF) responses

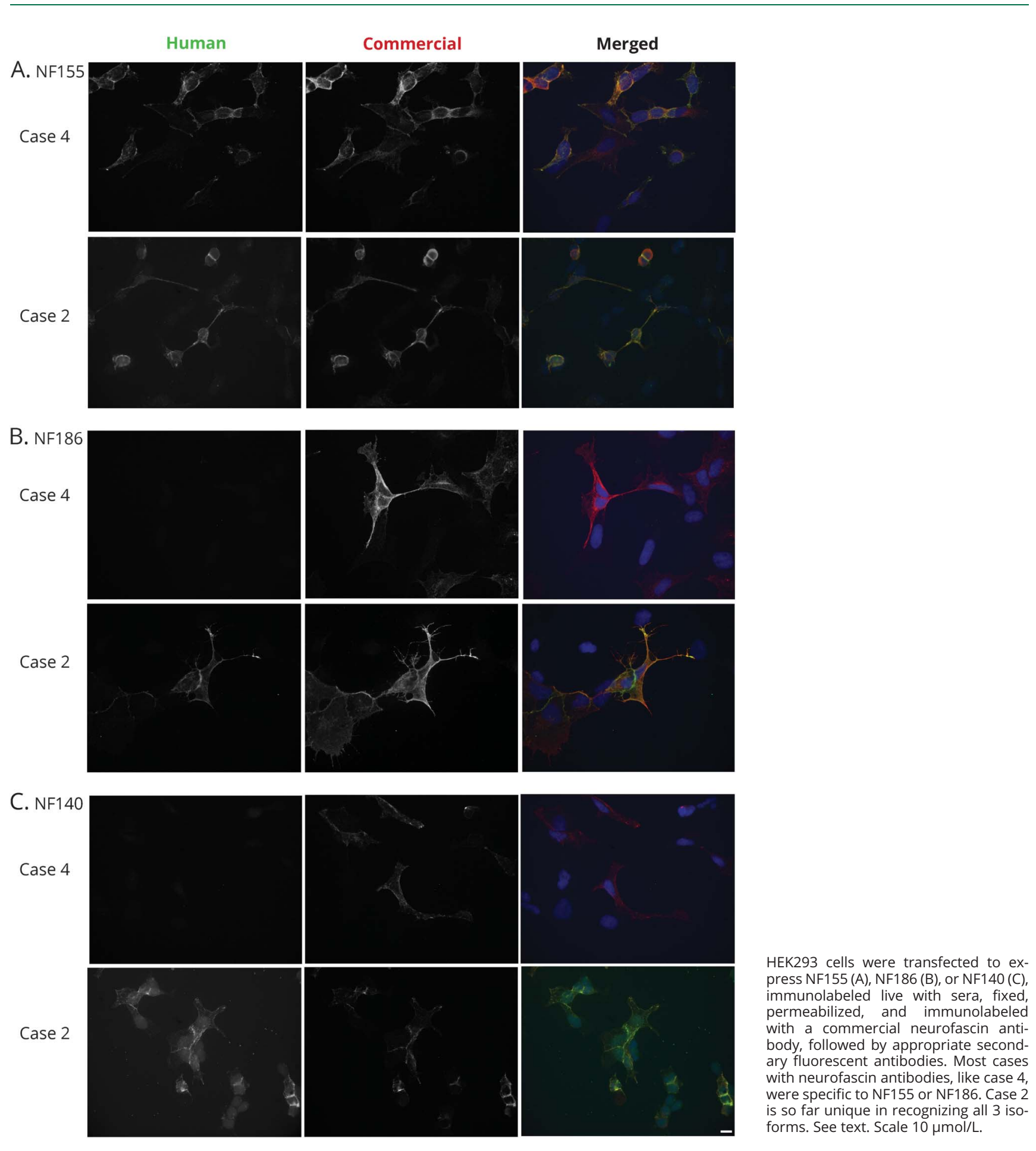

resembling GBS. Because immunoglobulins are thought to be progressively expressed by maturing $B$ cells in a specific order $(\mathrm{IgM} \rightarrow \mathrm{IgG} 3 \rightarrow \operatorname{IgG} 1 \rightarrow \operatorname{IgG} 2 \rightarrow \operatorname{IgG} 4),{ }^{18}$ it is likely that patients who have an IgG4 against NF155 started with an IgM against NF155. IgM responses to NF155 or NF186 were, however, found in several different groups of patients (those with idiopathic neuropathy, CMT, CIDP, and GBS), so they do not invariably progress to IgG4 responses. Additional studies are needed to determine whether patients with GBS with neurofascin IgM are at higher risk of progressing to CIDP or whether IgM antibodies contribute to pathogenesis.

In most cases, antibody responses were specific to either NF155 or NF186, consistent with prior studies showing that 
NF155 antibodies recognize the third and fourth fibronectinlike domains ${ }^{4}$ and that most NF155 antibodies recognize a glycosylated epitope in the first through fourth fibronectinlike domains. ${ }^{19}$ Case 2 had reactivity to an epitope shared by all 3 isoforms. This "pan-neurofascin" immune response could potentially affect both NF186 (localized to nodes) and NF155 (mostly localized to paranodes) and may account for the severe phenotype observed. Other patients with CIDP and antibodies to NF155 have been disabled and unable to ambulate, but the nearly locked-in state of our patient is unprecedented. It would be informative to study other patients with extremely severe CIDP for this antibody response. Additional studies may determine whether the disappearance of the neurofascin antibody response, as in this case, is a reliable biomarker of clinical CIDP remission. Even in the setting of profound disability, immune therapy and patience may lead to a significant recovery.

The NF155 IgG responses we observed were IgG4 predominant, matching prior reports. IgG4 antibodies have unique properties, including being functionally monovalent as a result of hemi-antibody exchange, having very high affinities, and not fixing complement. ${ }^{20}$ IgG4 antibodies to CAMs like neurofascins may act by disrupting their interactions with other CAMs. ${ }^{21}$ Testing for IgG4 to NF155, not just IgG to NF155, may increase the specificity of a positive finding for treatmentresistant CIDP.

By some estimates, almost half of patients with chronic progressive neuropathy are idiopathic, having no identifiable cause. $^{7,22}$ It is possible that some patients with idiopathic neuropathy may have an autoimmune cause even though they lack the distinctive clinical and electrophysiologic findings of GBS or CIDP. The possibility of an increased frequency of neurofascin antibodies in idiopathic compared to genetic neuropathy therefore requires further investigation.

Our work supports the concept that autoantibodies to peripheral nerve proteins such as neurofascins may define particular phenotypes and predict response to treatment. Our work also demonstrates that different types of antibody responses to the same antigen (IgM vs IgG, persistent vs transient) or antibody responses to different parts of the same protein (NF155-specific domains vs core neurofascin domains) have different prognostic implications.

\section{Author contributions}

E.B.: analyze data, draft manuscript. L.Y., Z.H., K.P., C.Q., M.R., and A.M.R.: analyze data. S.S.S.: Conceptualize experiments, analyze data, draft manuscript. E.L.: conceptualize experiments, analyze data, draft manuscript.

\section{Acknowledgment}

The authors thank their patients for their interest, their colleagues for referring patients, and Dr. Peter Brophy (University of Edinburgh) for generously sharing the plasmids for neurofascin isoforms, including NF140.

\section{Study funding}

Funding was provided by the University of Pennsylvania Department of Neurology and Precision Medicine Program, Grifols Inc, and NIH K08 NS-075142-01A1 (to E.L.) and the Shenghua Yuying Project of Central South University (L.Y.). A.M.R. is funded by a Wellcome Trust Postdoctoral Fellowship for Clinicians (110043/Z/15/Z). M.M.R is grateful to the Medical Research Council (MRC), MRC Centre (grant G0601943), and the National Institutes of Neurological Diseases and Stroke and office of Rare Diseases (U54NS065712) for their support.

\section{Disclosure}

E. Burnor, L. Yang, H. Zhou, K. Patterson, C. Quinn, M. Reilly, and A. Rossor report no disclosures relevant to the manuscript. S. Scherer has taught courses/lectured for Grifols, Inc. Dr. Lancaster has consulted for Janssen Inc and Amgen Inc; taught courses/lectured for Grifols, Inc, which manufactures IVIG with an indication for CIDP; received a grant from Grifols Inc; and consulted/testified for the US Vaccine Injury Compensation Program. Go to Neurology.org/N for full disclosures.

Received July 6, 2017. Accepted in final form September 26, 2017.

\section{References}

1. Devaux JJ, Odaka M, Yuki N. Nodal proteins are target antigens in Guillain-Barre syndrome. J Periph Nerv Syst 2012;17:62-71.

2. Querol L, Nogales-Gadea G, Rojas-Garcia R, et al. Neurofascin IgG4 antibodies in CIDP associate with disabling tremor and poor response to IVIg. Neurology 2014;82:879-886.

3. Querol L, Nogales-Gadea G, Rojas-Garcia R, et al. Antibodies to contactin-1 in chronic inflammatory demyelinating polyneuropathy. Ann Neurol 2013;73:370-380.

4. $\mathrm{Ng} \mathrm{JK}$, Malotka J, Kawakami N, et al. Neurofascin as a target for autoantibodies in peripheral neuropathies. Neurology 2012;79:2241-2248.

5. Kamamura N, Yamasaki R, Yonekawa T, et al. Anti-neurofascin antibody in patients with combined central and peripheral demyelination. Neurology 2013;81:714-722.

6. Sawai S, Satoh M, Mori M, et al. Moesin is a possible target molecule for cytomegalovirus-related Guillain-Barré syndrome. Neurology 2014;83:113-117.

7. Allen D, Giannopoulos K, Gray I, et al. Antibodies to peripheral nerve myelin proteins in chronic inflammatory demyelinating polyradiculoneuropathy. J Peripher Nervous Syst 2005;10:174-180.

8. Querol L, Rojas-Garcia R, Diaz-Manera J, et al. Rituximab in treatment-resistant CIDP with antibodies against paranodal proteins. Neurol Neuroimmunol Neuroinflamm 2015;2:e149.

9. Tait S, Gunn-Moore F, Collinson JM, et al. An oligodendrocyte cell adhesion molecule at the site of assembly of the paranodal axo-glial junction. J Cell Biol 2000;150:657-666.

10. Brown AA, Xu T, Arroyo EJ, et al. Molecular organization of the nodal region is not altered in spontaneously diabetic BB-Wistar rats. J Neurosci Res 2001;65:139-149.

11. Zhang A, Desmazieres A, Zonta B, et al. Neurofascin 140 is an embryonic neuronal neurofascin isoform that promotes the assembly of the node of Ranvier. J Neurosci 2015;35:2246-2254.

12. Katz JS, Saperstein DS, Gronseth G, Amato AA, Barohn RJ. Distal acquired demyelinating symmetric neuropathy. Neurology 2000;54:615-620.

13. Van den Bergh PY, Pieret F. Electrodiagnostic criteria for acute and chronic inflammatory demyelinating polyradiculoneuropathy. Muscle Nerve 2004;29:565-574

14. Mathey EK, Derfuss T, Storch MK, et al. Neurofascin as a novel target for autoantibody-mediated axonal injury. J Exp Med 2007;204:2363-2372.

15. Pruss H, Schwab JM, Derst C, Gortzen A, Veh RW. Neurofascin as target of autoantibodies in Guillain-Barre syndrome. Brain 2011;134:e173; author reply e174.

16. Mathey EK, Garg N, Park SB, et al. Autoantibody responses to nodal and paranodal antigens in chronic inflammatory neuropathies. J Neuroimmunology 2017;309:41-46.

17. Delmont E, Manso C, Querol L, et al. Autoantibodies to nodal isoforms of neurofascin in chronic inflammatory demyelinating polyneuropathy. Brain 2017;140:1851-1858.

18. Collins AM, Jackson KJ. A temporal model of human IgE and IgG antibody function. Front Immunol 2013;4:235.

19. Devaux JJ, Miura Y, Fukami Y, et al. Neurofascin-155 IgG4 in chronic inflammatory demyelinating polyneuropathy. Neurology 2016;86:800-807.

20. Huijbers MG, Querol LA, Niks EH, et al. The expanding field of IgG4-mediated neurological autoimmune disorders. Eur J Neurol 2015;22:1151-1161.

21. Labasque M, Hivert B, Nogales-Gadea G, Querol L, Illa I, Faivre-Sarrailh C. Specific contactin $\mathrm{N}$-glycans are implicated in neurofascin binding and autoimmune targeting in peripheral neuropathies. J Biol Chem 2014;289:7907-7918.

22. Hanewinckel R, Drenthen J, van Oijen M, Hofman A, van Doorn PA, Ikram MA Prevalence of polyneuropathy in the general middle-aged and elderly population. Neurology 2016;87:1892-1898 


\section{Neurofascin antibodies in autoimmune, genetic, and idiopathic neuropathies}

Elisabeth Burnor, BA, Li Yang, MD, Hao Zhou, MD, Kristina R. Patterson, MD, PhD, Colin Quinn, MD, MS, Mary M. Reilly, FRCP, FRCPI, MD, Alexander M. Rossor, MRCP, PhD, Steven S. Scherer, MD, PhD, and Eric Lancaster, MD, PhD

Neurology ${ }^{\circledast}$ 2018;90:21. doi:10.1212/WNL.0000000000004773

\author{
Correspondence \\ Dr. Lancaster \\ eric.lancaster@uphs. \\ upenn.edu
}

\section{Study funding/potential competing interests}

The study was funded by universities, the NIH, the UK Medical Research Council, Grifols Inc, and the Wellcome Trust. Some authors report providing educational and consulting services to pharmaceutical companies and the US Vaccine Injury Compensation Program. Go to Neurology.org/N for full disclosures.

\section{Study question}

What are the frequencies and clinical correlates of neurofascin antibodies in different peripheral neuropathies?

\section{Summary answer}

Neurofascin antibodies are more frequently observed in autoimmune neuropathies than in genetic neuropathies, and immunoglobulin G4 (IgG4) responses to neurofascin 155 (NF155) correlate with chronic inflammatory demyelinating polyneuropathy (CIDP) that is resistant to conventional treatments but responsive to rituximab.

\section{What is known and what this paper adds}

Autoantibodies against neurofascins on the membranes of axons and myelinating Schwann cells can occur in autoimmune neuropathies. This study provides evidence that neurofascin antibody profiles may provide guidance in diagnosing and treating neuropathies.

\section{Participants and setting}

The study analyzed cohorts with autoimmune neuropathies, namely CIDP and Guillain-Barré syndrome $(\mathrm{n}=54)$; genetic neuropathies $(n=111)$; and idiopathic neuropathies $(n=43)$. These cases were identified in a University of Pennsylvania tissue bank and at the UK National Hospital for Neurology and Neurosurgery.

\section{Design, size, and duration}

Antibodies against NF140, NF155, and NF186 were detected with a cell culture-based immunocytochemistry protocol. IgG1 through IgG4 were immunologically detected in the

\begin{tabular}{lll}
\hline Diagnosis & Cases, $\mathrm{n}$ & NF155 IgG4 \\
\hline CIDP & 5 & Present in 4 cases \\
\hline Guillain-Barré syndrome & 2 & Not present \\
\hline Acute motor axonal neuropathy & 1 & Not present \\
\hline Idiopathic neuropathy & 3 & Present minimally in 1 case \\
\hline Charcot-Marie-Tooth & 3 & Not present \\
\hline
\end{tabular}

same cell culture system. Researchers were not blinded for all evaluations. Between-group comparisons of antibody frequencies were performed with the Fisher exact test.

\section{Main results and the role of chance}

Neurofascin antibodies occurred significantly more frequently in the autoimmune neuropathies (14\%) than in the genetic neuropathies $(3 \%)(p=0.01)$. An intermediate frequency was observed in the idiopathic neuropathies (7\%). All 4 CIDP samples expressing anti-NF155 IgGs had IgG4-predominant responses. Three of them had responded poorly to IV immunoglobulin treatment but apparently responded well to rituximab, including 1 patient with antibodies to NF155, NF140, and NF186 who had a severe form of CIDP approaching a locked-in state.

\section{Bias, confounding, and other reasons for caution}

While NF155 IgG4 responses were associated with severe CIDP, other types of neurofascin antibodies may also be found in patients with nonautoimmune neuropathies and should be interpreted cautiously.

\section{Generalizability to other populations}

The association of antibodies to all neurofascin isoforms with an incredibly severe CIDP in a single patient should be interpreted with caution unless other similar cases are reported. 


\section{Neurology}

Neurofascin antibodies in autoimmune, genetic, and idiopathic neuropathies
Elisabeth Burnor, Li Yang, Hao Zhou, et al.

Neurology 2018;90;e31-e38 Published Online before print November 29, 2017

DOI 10.1212/WNL.0000000000004773

This information is current as of November 29, 2017

Updated Information \&
Services
References
Citations
Subspecialty Collections

Subspecialty Collections

Permissions \& Licensing

Reprints including high resolution figures, can be found at: http://n.neurology.org/content/90/1/e31.full

This article cites 22 articles, 11 of which you can access for free at: http://n.neurology.org/content/90/1/e31.full\#ref-list-1

This article has been cited by 4 HighWire-hosted articles: http://n.neurology.org/content/90/1/e31.full\#\#otherarticles

This article, along with others on similar topics, appears in the following collection(s):

Autoimmune diseases

http://n.neurology.org/cgi/collection/autoimmune_diseases

Autonomic diseases

http://n.neurology.org/cgi/collection/autonomic_diseases

Chronic inflammatory demyelinating polyneuropathy

http://n.neurology.org/cgi/collection/chronic_inflammatory_demyelinat ing_polyneuropathy

Guillain-Barre syndrome

http://n.neurology.org/cgi/collection/guillainbarre_syndrome

Information about reproducing this article in parts (figures,tables) or in its entirety can be found online at:

http://www.neurology.org/about/about_the_journal\#permissions

Information about ordering reprints can be found online:

http://n.neurology.org/subscribers/advertise

Neurology ${ }^{\circledR}$ is the official journal of the American Academy of Neurology. Published continuously since 1951, it is now a weekly with 48 issues per year. Copyright Copyright @ 2017 The Author(s). Published by Wolters Kluwer Health, Inc. on behalf of the American Academy of Neurology. All rights reserved. Print ISSN: 0028-3878. Online ISSN: 1526-632X.

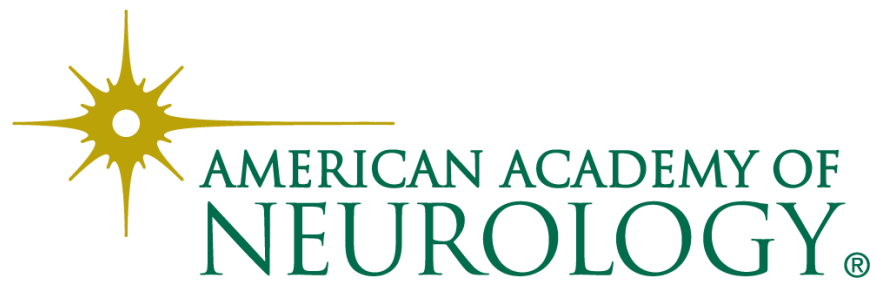

